\title{
Plasmodesmata spread their influence
}

\section{David Jackson}

Address: Cold Spring Harbor Laboratory, One Bungtown Road, Cold Spring Harbor, NY 11724, USA

Email: jacksond@cshl.edu

Fl000Prime Reports 2015, 7:25 (doi:10.12703/P7-25)

All FI000Prime Reports articles are distributed under the terms of the Creative Commons Attribution-Non Commercial License (http://creativecommons.org/licenses/by-nc/3.0/legalcode), which permits non-commercial use, distribution, and reproduction in any medium, provided the original work is properly cited.

The electronic version of this article is the complete one and can be found at: http://fl000.com/prime/reports/b/7/25

\begin{abstract}
Plasmodesmata (PDs) are microscopic channels that connect virtually every plant cell to its neighbors. They also provide a route for molecules to access the phloem for systemic movement throughout the plant. In this report, I review recent findings that broaden the potential impact of these channels, by revealing their contribution to auxin movement and as potential sites of receptor signaling. These discoveries should prompt a reassessment of symplasmic connectivity and its importance to plant development, defense, and physiology.
\end{abstract}

\section{Introduction}

Cell-to-cell communication is critical in multicellular development, and in plants numerous lineage studies have shown that cells differentiate according to their position rather than lineage, reinforcing the need for robust intercellular signals. PDs provide one possible route for intercellular signals and are composed of channels lined by a sleeve of plasma membrane with a tube of appressed endoplasmic reticulum running through the middle. Movement occurs predominantly through the cytoplasmic space between these membranes (reviewed in [1-10]). Although PD were discovered more than 100 years ago, their mode of regulation and the full impact of their functions are still a vigorous area of research. PD channels are thought to allow the free movement of water, metabolites, and other small molecules between cells. However, work during the past 15 years has clearly shown their importance in providing a means for cell-to-cell trafficking of regulatory proteins and RNAs. Several recent reviews have discussed the exciting areas of developmental and epigenetic regulation conditioned by local and systemic movement of proteins and RNAs [1-10]. For example, the establishment of specific cell types in the root and of lateral root primordia, spacing of trichomes and root hairs, maintenance of the shoot apical meristem, establishment of leaf polarity, and induction of flowering all depend on mobile protein or RNA signals or both. In this review,
I will focus on newer findings that broaden the potential impact of PD-mediated trafficking by suggesting that they contribute to maintenance of auxin gradients and act as sites of receptor-mediated signaling.

\section{Auxin movement through plasmodesmata}

Auxin is a key plant hormone that functions in many aspects of growth and development. Its distribution within tissues, particularly in gradients, is critical for its multiple functions. The auxin field has focused on auxin transport by transmembrane influx and efflux carriers; however, auxin is a small molecule and as such should be able to diffuse freely through the cytoplasmic channels of PDs. Indeed, a recent study has highlighted the importance of controlling PD permeability to maintain tissue auxin gradients. PDs are dynamically regulated by deposition of a $\beta$-1,3-glucan polymer, callose, in the cell wall around the PD [11-13]. This polymer reduces the PD permeability by physically restricting the pores when it accumulates. To understand which of the callose synthases might be involved in this regulation, mutants of the 12 Arabidopsis callose synthase homologs were screened for callose deposition at PDs [14]. Only one of them, glucan synthase-like 8/callose synthase 10 (gsl8/calS10), showed significant reduction in PD callose. Because gsl8-null mutants have cytokinesis defects and are seedling lethal, experiments were conducted with inducible gsl8 RNA interference (RNAi) 
lines. Upon induction, the seedlings showed phenotypes reminiscent of auxin defects, including a reduction in hypocotyl phototropism and gravitropism.

These tropisms are stimulated by changing the orientation of the seedlings with respect to gravity or light source, which leads to a rapid rearrangement of growth, away from gravity or toward light (Figure 1A). Hypocotyl tropisms are caused by auxin-gradient-induced cell expansion [15]. However, in seedlings where GSL8 expression was reduced, tropic growth did not occur (Figure 1B). Staining of callose revealed that, under normal circumstances, tropic stimulation rapidly induces callose at PDs (Figure 1C), on the shaded side of the hypocotyl where auxin accumulates. However, callose did not accumulate in GSL8 RNAi seedlings (Figure 1D). Indeed, in these seedlings, the level of callose at PDs was strongly reduced, and auxin movement, measured by using radiolabeled auxin, was enhanced. To independently test whether this effect was due to reduced callose, a callose synthesis inhibitor, 2-deoxy-D-glucose, was also employed. As predicted, treatment with this inhibitor similarly led to a reduction in photo- and gravitropism. Additional controls using inhibitors of polar auxin transport and of auxin synthesis further supported the idea that changes in auxin distribution in GSL8 RNAi plants were caused by changes in PD permeability to auxin. Taken together, these findings imply that plants need to restrict the permeability of their PD channels, using callose, in order to establish or maintain auxin gradients.

The investigators next asked how callose deposition might be spatially and temporally controlled since this obviously needs to be highly dynamic. It was noticed that GSL8 expression was closely correlated with that of the DR5 auxin response reporter in the shaded-side epidermis of photo-stimulated seedlings. Treatment with auxin led to the upregulation of GSL8, even in the presence of the translation inhibitor cycloheximide, suggesting that GSL8 might be a direct transcriptional target of the auxin response. Indeed, auxin response factor7 (arf7) mutants, which are unable to respond to auxin-dependent tropic signals, were unable to upregulate GSL8 in response to auxin. The GSL8 promoter contains an ARF7-binding site, and chromatin immunoprecipitation assays confirmed that ARF7 could bind to it. Furthermore, when this ARF7-binding site was mutated, the mutated GSL8 construct was no longer able to rescue phototropic curvature in a gsl 8 mutant background. Indeed, it appeared that direct induction of GSL8 by auxin/ARF7 was important for the phototropic response.

Figure I. Impact of plasmodesma (PD) callose on auxin-induced phototropism and on lateral root initiation

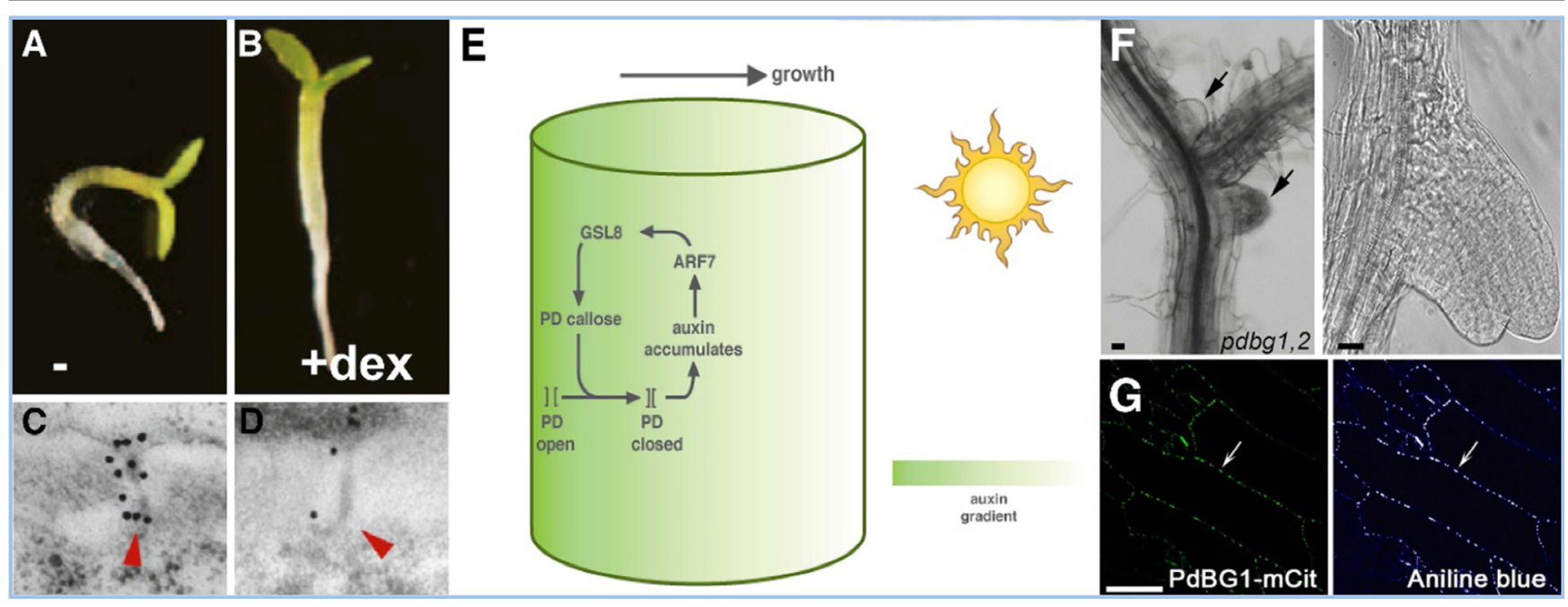

Normal Arabidopsis seedlings show phototropic bending (A) but a reduction in GSL8 expression prevents phototropism (B) and a reduction leads to a reduced level of callose in PDs; wildtype is shown in (C) and GSL8 RNAi line in (D). Black dots are gold particles coupled to anti-callose antibodies. Frames (A-D) are reproduced with permission from Elsevier [I4]. (E) A model to illustrate the positive feedback between auxin and PD callose on phototropism. On the shaded side of the hypocotyl (away from the sun), auxin induces GSL8, leading to callose deposition and reduced movement of auxin through PDs, thereby maintaining the auxin gradient. The effect is to promote growth toward the (sun)light. (F) The effect of increasing callose deposition in, plasmodesmal-localized $\beta$-I,3 glucanase ( $p d b g) I, 2$ mutants is seen in irregular, clustered, and fused lateral root primordia. The enzyme responsible, PdBGI, co-localizes with aniline blue staining, presumably at PDs (G). Frames $(F)$ and $(G)$ are reproduced with permission from Elsevier [18]. 
The experiments so far built a solid case to implicate GSL8, and the callose it produces, in maintenance of auxin gradients required for tropic growth. However, one caveat is that the GSL8 and callose manipulations might affect overall growth and therefore limit the capacity for tropic growth. This possibility was in part excluded in experiments where GSL8 was overexpressed. Lines with moderate overexpression indeed accumulated more callose and still showed enhanced phototropism [14].

These findings are very exciting and should stimulate auxin researchers to think more carefully about alternate movement routes. PD modulation of auxin gradients is attractive because callose deposition occurs extremely fast, within minutes [16]. As the authors point out, auxin might also control the trafficking of larger molecules through PDs [14]. It will be especially interesting to ask whether auxin gradients in other developmental contexts are also affected by PD permeability (for example, in the shoot apical meristem, where auxin distribution is required for leaf initiation and discrete symplasmic domains have been found [17]). Indeed, other plant hormones and small signaling molecules are also likely to move relatively unimpeded through PDs, so there is much to do and learn in this exciting new area. For example, it would be of interest to find out how light controls GSL8 expression or whether auxin-mediated PD regulation affects movement of proteins or RNAs. It is also important to consider whether auxin-mediated PD closure might impede transport of metabolites that are essential for growth.

A second recent example also highlights the importance of PD-localized callose regulation in development, this time in morphogenesis and lateral root architecture [18]. Just as PD-localized callose synthesis by GSLs is tightly regulated, callose degradation by PD-localized $\beta-1,3$ glucanases (PdBGs) also appears to be exquisitely controlled during development. This story started with a survey of symplasmic connectivity during lateral root development. It was found, using a pSUC2-GFP (green fluorescent protein) reporter, that GFP could move cell-to-cell during early and late stages of lateral root formation, but in intermediate stages (stage IV-V), the cells were symplasmically isolated from GFP diffusion. A previous "PD proteome" screen had identified 13 putative PD-localized $\beta$-1,3-glucanases, enzymes that are known to degrade callose [18]. Expression data indicated that one of these, named PdBG1, along with a close homolog, PdGB2, was expressed during lateral root initiation. Expression of fluorescent protein fusions confirmed that PdBG1 localized to PDs (Figure 1G). pdbg1,2 double mutants were found to have increased callose deposition and restricted GFP cell-to-cell movement. Concomitant with this change in symplasmic connectivity, the double mutants had dramatic changes in lateral root initiation; the primordia were clustered and often fused (Figure 1F). Confirmation that this effect was due to increased callose came from independent methods of callose induction, which led to similar phenotypes [18]. This story, like the one with GSL8, again illustrates how exquisite developmental control of PD permeability is necessary for proper development. Additional parallels can be drawn; for example, auxin is also a signal in lateral root initiation, so it will be interesting to see how PdBG expression affects auxin movement, although other mobile signals might also be affected. It will be of particular interest to study the dynamics of auxin maxima in the PdBG1 system and to consider the interplay between callose synthesis and degradation in this and other developmental contexts.

\section{Receptor signaling at plasmodesmata}

Another emerging area is the findings that several transmembrane proteins are enriched at PDs. The origin of this discovery is in proteomic studies, in which PDenriched cell-wall fractions were subjected to bulk proteomic analysis and predicted membrane proteins were characterized [19-26]. Some of these are involved in defense signaling and have been reviewed recently [27-29]. Here, I will focus on receptor-like kinases (RLKs) that function in developmental signaling and have been found at PDs mostly by chance. These include CRINKLY4 (CR4), which functions in aleurone specification in maize [30]; CLAVATA1 (CLV1) [31,32]; and STRUBBELIG (SUB), which functions in tissue morphogenesis by coordinating development between cell layers [33]. The molecular details of SUB signaling, including its ligand, are largely unknown, although it interacts with a membrane-bound C2 domain protein, QUIRKY (QKY), that also localizes to PDs [33].

In the shoot apical meristem, the CLV1 receptor kinase is activated by the extracellular ligand CLV3 and signals to repress the expression of the WUSCHEL (WUS) homeobox gene in the meristem organizing center. In clv1 mutants, loss of this repression leads to the overproliferation of stem cells and meristem overgrowth (or fasciation). A recent report indicates that $C L V 1$ also functions in root stem cell specification, in particular in the columella stem cells that produce part of the root cap [31]. Previously, another RLK, ACR4 (the Arabidopsis ortholog of maize CRINKLY4), had been localized to these cells and was found to have a similar function in controlling proliferation in the columella cell lineage; mutants in CLV1 or ACR4 similarly lead to additional layers of columella stem cells. Double-mutant analysis suggested that these 
receptors work in the same pathway along with their putative ligand, CLE 40 [31]. Interestingly, functional fluorescent protein fusions of the two receptors localized to the plasma membrane, as expected, but were also enriched at PDs, where the two receptors interact (Figure 2).

There are multiple reasons why RLKs might be enriched at PDs. The first, and perhaps least interesting, could be an effect of different rates of receptor endocytosis or recycling at the $\mathrm{PD}$, compared with other regions of the plasma membrane. CLV1 signaling, for example, is controlled by endocytosis [34]. It would be of interest to use super-resolution microscopy [35] to ask where in the PD structure the receptors are accumulating. For example, the plasma membrane domain deep within the PD channel might be protected from endosomal trafficking, but the plasma membrane around the neck region might be a site enriched in receptor recycling to the membrane. Indeed, viral and endogenous trafficking proteins are known to subvert vesicle trafficking machineries $[36,37]$.

A second reason for the observed enrichment of receptors at PDs is that they could function as a signaling center or hub, where receptors and downstream signaling proteins are concentrated. Similar signaling centers have been described in other systems (for example, in vertebrate hedgehog signaling, which occurs at cellular protrusions, called primary cilia, that are present on most mammalian cells) $[38,39]$. Similarly, the concentration of signaling proteins at cilia has been described in the mating pathway in Chlamydomonas [39]. This enrichment of signaling components at cilia has two possible explanations: the cilia could act simply as scaffolds, to assemble signaling complexes, or alternatively they could act to increase the local concentration of signaling molecules and enhance signaling efficiency [39].

A third, more exciting, possibility is that signaling by PD localized receptors results in a direct modification of PD function. This could happen in a relatively non-specific fashion, by altering the PD permeability (for example, by regulation of GSLs or PdBGs, discussed earlier). This could affect the movement of smaller molecules, including hormones like auxin, as well as general movement of protein or RNA signals or both. Alternatively, regulation might occur in a more specific manner (for example, by

Figure 2. Localization of receptor-like kinases (RLKs) to plasmodesmata (PDs) and their possible consequences
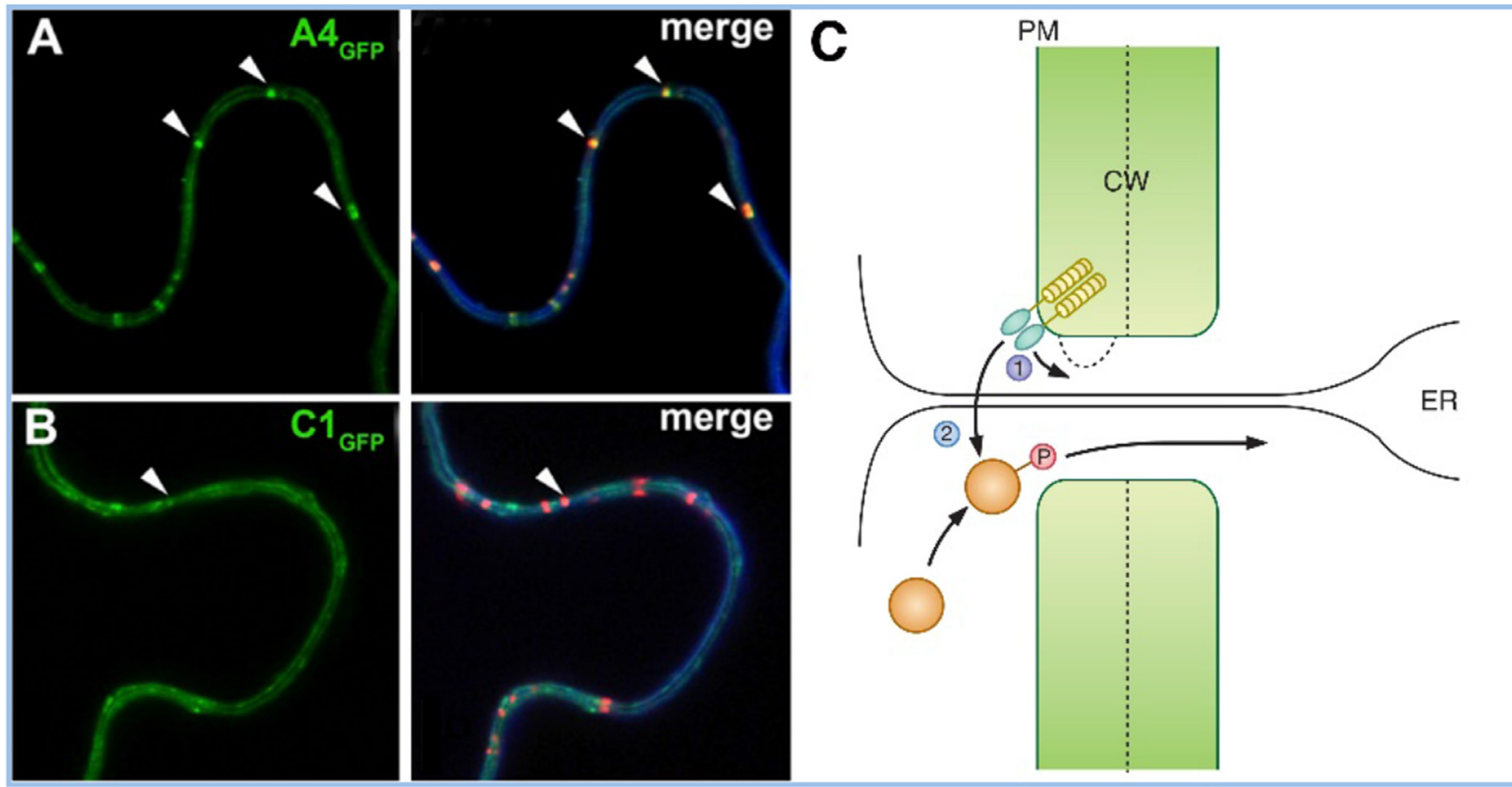

Green fluorescent protein (GFP) fusions of ACR4 (A) and CLVI (CLAVATAI) (B) show plasma membrane and PD-enriched localization (arrow) in the left panels. The right panels show co-localization with a membrane stain, FM4-64 (blue), and aniline blue staining for callose (red). Reproduced with permission from Elsevier [3I]. A4, ACR4; CI, CLVI. (C) Two models for the role of RLKs in PD function are proposed: in (I), RLK signaling could control callose deposition and PD permeability; in (2), the RLK could phosphorylate a non-cell autonomous protein, which could allow it to traffic through the PD or restrict its trafficking in the destination cell or do both. Abbreviations: CW, cell wall; ER, endoplasmic reticulum; PM, plasma membrane 
controlling the trafficking of specific proteins or RNAs) [32]. A precedent for this type of regulation is seen in the first described mobile proteins, viral movement proteins, whose movement appears to be controlled by PD localized kinases [40]. In this regard, the similarity of QKY to FLOWERING LOCUS T-INTERACTING PROTEIN 1 (FTIP1), a protein that controls trafficking of the floral-inducing protein FT [41], suggests that SUB RLK might also interact with FTIP1 and that the interaction of the SUB with QKY/FTIP1 might control trafficking of FT-related or other proteins. Indeed, since FT is thought to act as a general growth regulator rather than a specific regulator of flowering [42], such a mechanism could have broad implications in the coordination of growth across tissues. Another candidate for this model is the mobile protein ANGUSTIFOLIA3 (AN3), which controls leaf growth. Movement of AN3 between cell layers is controlled by an as-yet-unknown mechanism [43]. In the case of ACR4/CLV1 localization to PDs, an exciting possibility is that they might control cell-to-cell movement of WUS-related transcription factors, such as WUSCHEL-RELATED HOMEOBOX 5 (WOX5), which plays a similar role in the root as WUS does in the shoot. Indeed, WUS protein has been found to move, most likely through PDs, as part of its function in meristem maintenance $[44,45]$.

Whatever the purpose of receptor localization to PDs, it will be important to show its functional significance. For example, swapping the transmembrane domain [19] could re-localize the receptor to the entire plasma membrane without being enriched at PDs, and these constructs could be subjected to functional tests. However, one caveat is that the mislocalization away from PDs might interrupt interaction with other receptors or signaling components. Whatever the outcome, the finding of receptors enriched at PDs opens up many new questions about how they function and about potential targets.

In recent years, auxin signaling and meristem maintenance have been subjected to quantitative mathematical modeling $[46,47]$, and it is certainly time that the potential impact of PDs be included in these models. The many potential layers of crosstalk between PDs, auxin, and receptor-based signaling add new complexities to plant physiology, defense, and development. But nobody said that things would be simple!

\section{Abbreviations}

AN3, ANGUSTIFOLIA3; ARF7, auxin response factor7; CLV1， CLAVATA1; FTIP1， FLOWERING LOCUS T-INTERACTING PROTEIN 1; GFP, green fluorescent protein; GSL8, glucan synthase-like 8; PD, plasmodesma; PdBG, plasmodesmal-localized $\beta-1,3$ glucanase; QKY,
QUIRKY; RLK, receptor-like kinase; RNAi, RNA interference; SUB, STRUBBELIG; WUS, WUSCHEL.

\section{Disclosures}

The author declares that he has no disclosures.

\section{Acknowledgments}

I would like to thank Huyen Thanh Bui and Rachappa Balkunde for comments on this review. Research on plasmodesmata in David Jackson's lab is funded by the National Science Foundation.

\section{References}

I. Xu XM, Jackson D: Lights at the end of the tunnel: new views of plasmodesmal structure and function. Current opinion in plant biology 2010, 13:684-92.

2. Ueki S, Citovsky V: To gate, or not to gate: regulatory mechanisms for intercellular protein transport and virus movement in plants. Molecular plant 2011 , 4:782-93.

3. Maule AJ, Benitez-Alfonso Y, Faulkner C: Plasmodesmata - membrane tunnels with attitude. Current opinion in plant biology 20I I, I4:683-90.

4. Wu S, Gallagher KL: Transcription factors on the move. Current opinion in plant biology 2012, 15:645-5I.

5. Brunkard JO, Runkel AM, Zambryski PC: Plasmodesmata dynamics are coordinated by intracellular signaling pathways. Current opinion in plant biology 2013, 16:614-20.

6. Burch-Smith TM, Zambryski PC: Plasmodesmata paradigm shift: regulation from without versus within. Annual review of plant biology 2012, 63:239-60.

7. Hannapel DJ: Long-Distance Signaling via Mobile RNAs. In LongDistance Systemic Signaling and Communication in Plants. Edited by Baluška F. Berlin, Heidelberg: Springer Berlin Heidelberg; 201 3:53-70 [Signaling and Communication in Plants].

8. Kragler F: Plasmodesmata: intercellular tunnels facilitating transport of macromolecules in plants. Cell and tissue research 2013, 352:49-58

9. Yadav SR, Yan D, Sevilem I, Helariutta Y: Plasmodesmata-mediated intercellular signaling during plant growth and development. Frontiers in plant science 2014, 5:44.

10. Ham B, Lucas WJ: The angiosperm phloem sieve tube system: a role in mediating traits important to modern agriculture. Journal of experimental botany 2014, 65:1799-816.

II. Benitez-Alfonso Y, Cilia M, San Roman A, Thomas C, Maule A, Hearn S, Jackson D: Control of Arabidopsis meristem development by thioredoxin-dependent regulation of intercellular transport. Proceedings of the National Academy of Sciences of the United States of America 2009, 106:3615-20.

\section{FlOOOPrime} RECOMMENDED

12. Vatén A, Dettmer J, Wu S, Stierhof $Y$, Miyashima S, Yadav SR, Roberts CJ, Campilho A, Bulone V, Lichtenberger R, Lehesranta S, Mähönen AP, Kim J, Jokitalo E, Sauer N, Scheres B, Nakajima K, Carlsbecker A, Gallagher KL, Helariutta Y: Callose biosynthesis regulates symplastic trafficking during root development. Developmental cell 201 I, 2 I: I |44-55.

\section{FlOOPrime}

\section{RECOMMENDED}

13. Zavaliev R, Levy A, Gera A, Epel BL: Subcellular dynamics and role of Arabidopsis $\beta$-I,3-glucanases in cell-to-cell movement of tobamoviruses. Molecular plant-microbe interactions: MPMI 20I3, 26: $1016-30$.

14. Han X, Hyun TK, Zhang M, Kumar R, Koh E, Kang B, Lucas WJ, Kim J: Auxin-callose-mediated plasmodesmal gating is essential for 
tropic auxin gradient formation and signaling. Developmental cell 2014, 28:132-46.

FIOOOPrime
RECOMMENDED

15. Friml J, Wiśniewska J, Benková E, Mendgen K, Palme K: Lateral relocation of auxin efflux regulator PIN3 mediates tropism in Arabidopsis. Nature 2002, 41 5:806-9.

\section{FlOOOPrime} RECOMMENDED

16. Jaffe MJ, Leopold AC: Callose deposition during gravitropism of Zea mays and Pisum sativum and its inhibition by 2-deoxy-Dglucose. Planta 1984, 16 I:20-6.

17. Rinne PL, van der Schoot, C: Symplasmic fields in the tunica of the shoot apical meristem coordinate morphogenetic events. Development (Cambridge, England) 1998, I 25:1477-85.

18. Benitez-Alfonso Y, Faulkner C, Pendle A, Miyashima S, Helariutta Y, Maule A: Symplastic intercellular connectivity regulates lateral root patterning. Developmental cell 2013, 26:136-47.

\section{FlOOOPrime} RECOMMENDED

19. Thomas CL, Bayer EM, Ritzenthaler C, Fernandez-Calvino L, Maule AJ: Specific targeting of a plasmodesmal protein affecting cell-tocell communication. PLoS biology 2008, 6:e7.

\section{FlOOOPrime}

\section{RECOMMENDED}

20. Amari K, Boutant E, Hofmann C, Schmitt-Keichinger C, FernandezCalvino L, Didier P, Lerich A, Mutterer J, Thomas CL, Heinlein M, Mély Y, Maule AJ, Ritzenthaler C: A family of plasmodesmal proteins with receptor-like properties for plant viral movement proteins. PLoS pathogens 2010, 6:el001 II9.

\section{FlOOOPrime \\ RECOMMENDED}

21. Fernández $V$, Khayet $M$, Montero-Prado $P$, Heredia-Guerrero JA, Liakopoulos G, Karabourniotis G, Del Río V, Domínguez E, Tacchini I, Nerín C, Val J, Heredia A: New insights into the properties of pubescent surfaces: peach fruit as a model. Plant physiology $201 \mathrm{I}$, I56:2098-108.

22. Lee J, Wang X, Cui W, Sager R, Modla S, Czymmek K, Zybaliov B, van Wijk K, Zhang C, Lu H, Lakshmanan V: A plasmodesmata-localized protein mediates crosstalk between cell-to-cell communication and innate immunity in Arabidopsis. The Plant cell 201 I , 23:3353-73.

\section{FlOOOPrime
RECOMMENDED}

23. Jo Y, Cho WK, Rim Y, Moon J, Chen X, Chu H, Kim CY, Park Z, Lucas WJ, Kim J: Plasmodesmal receptor-like kinases identified through analysis of rice cell wall extracted proteins. Protoplasma 201 I, 248:191-203.

\section{FlOOOPrime}

\section{RECOMMENDED}

24. Ham B, Li G, Kang B, Zeng F, Lucas WJ: Overexpression of Arabidopsis plasmodesmata germin-like proteins disrupts root growth and development. The Plant cell 2012, 24:3630-48.

\section{FlOOOPrime}

\section{RECOMMENDED}

25. Faulkner C, Petutschnig E, Benitez-Alfonso Y, Beck M, Robatzek S, Lipka V, Maule AJ: LYM2-dependent chitin perception limits molecular flux via plasmodesmata. Proceedings of the National Academy of Sciences of the United States of America 20 I 3, I I 0:91 66-70.

\section{FlOOOPrime \\ RECOMMENDED}

26. Wang $X$, Sager $R$, Cui $W$, Zhang $C$, Lu H, Lee J: Salicylic acid regulates Plasmodesmata closure during innate immune responses in Arabidopsis. The Plant cell 2013, 25:2315-29.
27. Maule A, Faulkner C, Benitez-Alfonso Y: Plasmodesmata "in Communicado". Frontiers in plant science 2012, 3:30.

28. Faulkner C: Receptor-mediated signaling at plasmodesmata. Frontiers in plant science 2013, 4:521.

29. Lee J: New and old roles of plasmodesmata in immunity and parallels to tunneling nanotubes. Plant science: an international journal of experimental plant biology 2014, 22 I-222: I3-20.

30. Tian Q, Olsen L, Sun B, Lid SE, Brown RC, Lemmon BE, Fosnes K, Gruis DF, Opsahl-Sorteberg H, Otegui MS, Olsen O: Subcellular localization and functional domain studies of DEFECTIVE KERNELI in maize and Arabidopsis suggest a model for aleurone cell fate specification involving CRINKLY4 and SUPERNUMERARY ALEURONE LAYERI. The Plant cell 2007, 19:3 I 27-45.

\section{FlOOOPrime}

\section{RECOMMENDED}

3I. Stahl Y, Grabowski S, Bleckmann A, Kühnemuth R, WeidtkampPeters S, Pinto KG, Kirschner GK, Schmid JB, Wink RH, Hülsewede A, Felekyan S, Seidel, Claus AM, Simon R: Moderation of Arabidopsis root stemness by CLAVATAI and ARABIDOPSIS CRINKLY4 receptor kinase complexes. Current biology: CB 20I3, 23:362-7I.

\section{FlOOOPrime
RECOMMENDED}

32. Stahl Y, Simon R: Gated communities: apoplastic and symplastic signals converge at plasmodesmata to control cell fates. Journal of experimental botany 2013, 64:5237-41.

33. Vaddepalli P, Herrmann A, Fulton L, Oelschner M, Hillmer S, Stratil TF, Fastner A, Hammes UZ, Ott T, Robinson DG, Schneitz K: The C2-domain protein QUIRKY and the receptor-like kinase STRUBBELIG localize to plasmodesmata and mediate tissue morphogenesis in Arabidopsis thaliana. Development (Cambridge, England) 2014, 141:4139-48.

\section{FlOOOPrime}

RECOMMENDED

34. Nimchuk ZL, Tarr PT, Ohno C, Qu X, Meyerowitz EM: Plant stem cell signaling involves ligand-dependent trafficking of the CLAVATAI receptor kinase. Current biology: CB 20I I, 2 I:345-52.

\section{FlOOOPrime}

RECOMMENDED

35. Fitzgibbon J, Bell K, King E, Oparka K: Super-resolution imaging of plasmodesmata using three-dimensional structured illumination microscopy. Plant physiology 2010, I 53:|453-63.

\section{FlOOOPrime}

RECOMMENDED

36. Haupt S, Cowan GH, Ziegler A, Roberts AG, Oparka KJ, Torrance L: Two plant-viral movement proteins traffic in the endocytic recycling pathway. The Plant cell 2005, I 7: I64-8I.

\section{FlOOOPrime}

\section{RECOMMENDED}

37. Wu S, Gallagher KL: The movement of the non-cell-autonomous transcription factor, SHORT-ROOT relies on the endomembrane system. The Plant journal: for cell and molecular biology 2014, 80:396-409.

\section{FlOOOPrime
RECOMMENDED}

38. Jin H, White SR, Shida T, Schulz S, Aguiar M, Gygi SP, Bazan JF, Nachury MV: The conserved Bardet-Biedl syndrome proteins assemble a coat that traffics membrane proteins to cilia. Cell 2010, 141:1208-19.

\section{FlOOOPrime}

\section{RECOMMENDED}

39. Nachury MV: How do cilia organize signalling cascades? Philosophical transactions of the Royal Society of London. Series B, Biological sciences 2014, 369. 
40. Lee J, Taoka K, Yoo B, Ben-Nissan G, Kim D, Lucas W]: Plasmodesmal-associated protein kinase in tobacco and Arabidopsis recognizes a subset of non-cell-autonomous proteins. The Plant cell 2005, 17:2817-3I.

\section{FlOOOPrime \\ RECOMMENDED}

4I. Liu L, Liu C, Hou X, Xi W, Shen L, Tao Z, Wang Y, Yu H: FTIPI is an essential regulator required for florigen transport. PLoS biology 2012, 10:e1001313

\section{FlOOOPrime}

\section{RECOMMENDED}

42. Shalit A, Rozman A, Goldshmidt A, Alvarez JP, Bowman JL, Eshed Y, Lifschitz E: The flowering hormone florigen functions as a general systemic regulator of growth and termination. Proceedings of the National Academy of Sciences of the United States of America 2009, 106:8392-7.

\section{FlOOOPrime}

RECOMMENDED

43. Kawade K, Horiguchi G, Usami T, Hirai MY, Tsukaya H: ANGUSTIFOLIA3 signaling coordinates proliferation between clonally distinct cells in leaves. Current biology: CB 2013, 23: 788-92.

FIOOOPrime

44. Yadav RK, Perales M, Gruel J, Girke T, Jönsson H, Reddy GV: WUSCHEL protein movement mediates stem cell homeostasis in the Arabidopsis shoot apex. Genes \& development 201 I, 25:2025-30.

\section{FlOOOPrime}

\section{RECOMMENDED}

45. Daum G, Medzihradszky A, Suzaki T, Lohmann JU: A mechanistic framework for noncell autonomous stem cell induction in Arabidopsis. Proceedings of the National Academy of Sciences of the United States of America 20 I4, I I I: |4619-24.

\section{FlOOOPrime}

RECOMMENDED

46. Cunha A, Tarr PT, Roeder, Adrienne HK, Altinok A, Mjolsness E, Meyerowitz EM: Computational analysis of live cell images of the Arabidopsis thaliana plant. Methods in cell biology 2012, I 10:285-323.

47. Krupinski $\mathrm{P}$, Jönsson $\mathrm{H}$ : Modeling auxin-regulated development. Cold Spring Harbor perspectives in biology 2010, 2:a001560. 